\title{
Mechanism of Dust Generation in a Converter with Minimum Slag
}

\author{
Ryoji TSUJINO, ${ }^{1)}$ Masazumi HIRAI, ${ }^{2)}$ Takamasa OHNO, ${ }^{\text {() }}$ Nobuyuki ISHIWATA ${ }^{4)}$ and Tsutomu INOSHITA ${ }^{5}$
}

1) Kimitsu R \& D Div., Nippon Steel Corporation, Kimitsu, Kimitsu, Chiba-ken, 299-11 Japan. $\quad$ 2) Kimitsu R \& D Div., NSC. Now at RHEO-TECHNOLOGY, Ltd., Kawasaki-cho, Chiba, Chiba-ken, 260 Japan. $\quad 3)$ Sakai R \& D Div., Nippon Steel Corporation, Chikkoyawata-cho, Sakai, Osaka-fu, 590 Japan. $\quad$ 4) Kimitsu Works, Nippon Steel Corporation, Kimitsu, Kimitsu, Chiba-ken, 299-11 Japan. 5) Yawata Works, Nippon Steel Corporation, Edamitsu, Yahatahigashi-ku, Kitakyushu, Fukuoka-ken, 805 Japan.

(Received on May 17, 1988; accepted in the final form on October 14, 1988)

\begin{abstract}
A study was made on the mechanism of dust generation by investigation of dust behavior in a BOF with combined blowing.
The results are summarized as follows:

(1)BOF dust is generated through "fumes" condensing and mixing with "burst bubble particles".

(2)The ratio of burst bubble particles in the dust is a little bit larger at the initial stage of blowing and decreases with the lapse of blowing time, whilst at the end of blowing, the ratio of fumes increases.

Therefore, if there are any effective step for reducing the quantity of dust generation, they might be the formation of slag in an early time at the initial stage of blowing and the cool down of a hot spot from the middle stage of blowing.
\end{abstract}

KEY WORDS: dust; fumes; basic oxygen steelmaking.

\section{Introduction}

By virtue of the development in a hot metal pretreatment technology and the technology of BOF combined blowing, BOF blowing with minimum slag has become possible and at the same time, iron loss into the slag has been remarkably reduced. Accordingly, the ratio of dust accounted in the iron loss of $\mathrm{BOF}$ has increased and in terms of the improvement in the iron yield, how to decrease the quantity of dust generated has become an important problem to be solved. $\mathrm{Up}_{\mathrm{p}}$ to now, there has been a variety of researches ${ }^{1-9)}$ conducted on dust generated in the steelmaking process and with regard to the mechanism of dust generation, there have typically been two views. One view ${ }^{1-6)}$ is that a source of dust generation lies in evaporation of $\mathrm{Fe}$ (hereinafter, the product is called as "fumes"). The other one $e^{7,8)}$ is that granulated iron scatters around through spitting or bubbles from the molten metal surface and some of them are further turning into fine particles by the reaction with the atmosphere in the furnace (hereinafter, the product is called as "burst bubble particle") and becoming dust. However at present, there is no unified view.

There have been few systematic researches on the dust generation in an actual BOF with combined blowing as well as the method of reducing the quantity of dust generated. It is essential to examine the factors causing the generation of dust and besides, to look into the mechanism of dust generation. From such viewpoint, the behavior of dust generation in an actual BOF with combined blowing was investigated.

\section{Experimental Methods}

At the front of a coarse particle separator in the OG dust collectors at 300-t, 250-t and 175-t BOFs with combined blowing, dust laden water was sampled at 2-min intervals during the period from the start to the end of blowing to extract dust contained in the water.

As will be stated hereinafter, an attempt was also made to obtain the ratio of burst bubble particles in the quantity of dust coming out during the blowing process by adding Mo having a very low vapor pressure ${ }^{16)}$ relative to $\mathrm{Fe}$ into the hot metal prior to $\mathrm{BOF}$ blowing. This is because of the idea that both fumes and burst bubble particle are concerning to a generation mechanism of BOF dust. For an Mo addition test, three heats were produced and in one heat, Mo was added in a form of Fe-Mo alloy (Mo of about $62 \%$ and $\mathrm{Fe}$ of about $38 \%$ ) and in the other two heats, it was done in a form of a molybdic ore $\left(\mathrm{MoO}_{3}\right.$ : Mo of about $61 \%$ and $\mathrm{O}$ of about $39 \%$ ). Moreover, $\mathrm{MoO}_{3}$ has higher vapor pressure ${ }^{16}$ than $\mathrm{Fe}$ and in the test performed by adding the molybdic ore, it is thought that $\mathrm{MoO}_{3}$ evaporates from the slag or bath before being reduced and mixes with the dust. Therefore, the data only at the end of BOF blow when the reduction is supposed to be finished have been employed. The sampled dust was subjected to chemical analysis, observation by optical microscope (hereinafter referred to as a microscope) and electron microscope, quantitative analysis by EPMA, measurement of particle size distribution and so on.

For measurement by EPMA, the sampled dust was impregnated with resin under vacuum and then ground. In the measurement by EPMA, spot-analysis was made of dust over $0.5 \mu \mathrm{m}$ in particle size with EPMA acceleration voltage set to $15 \mathrm{kV}$ and a line scan analysis was made of dust under $0.5 \mu \mathrm{m}$ in particle size with EPMA acceleration voltage set to 12 $\mathrm{kV}$ which is near the X-ray generating limit. ${ }^{21}$

In the respective cases, proper steps were taken not 
to allow X-ray generating depth to become excessively large relative to the size of dust particle for minimizing errors in measurement as much as possible.

Further, when studying the mechanism of dust generation, a decarburization test ${ }^{19)}$ in a $20 \mathrm{~kg}$ smelting furnace was performed with the addition of Mo and $\mathrm{Pt}$ having lower vapor pressure ${ }^{16)}$ than Fe. The behaviors of Mo and Pt contained in dust were investigated.

\section{Experimental Results}

\subsection{Composition of Dust Components}

Table 1 shows a typical example of average composition of components obtained by sampling dust at 2-min intervals of the blowing time, totaling and chemically analyzing. More than $90 \%$ are metallic iron (hereinafter referred to as $\mathrm{M} \cdot \mathrm{Fe}$ ) and an iron oxide of $\mathrm{FeO}$ and $\mathrm{Fe}_{2} \mathrm{O}_{3}$. The remaining components are manganese (hereinafter referred to as $\mathrm{T} \cdot \mathrm{Mn}$ ), $\mathrm{C}, \mathrm{CaO}, \mathrm{SiO}_{2}, \mathrm{MgO}$ and $\mathrm{P}_{2} \mathrm{O}_{5}$. In a total iron (hereinafter referred to as $\mathrm{T} \cdot \mathrm{Fe}$ ) , $\mathrm{Fe}_{2} \mathrm{O}_{3}$ is only a few percents and the bulk is $\mathrm{M} \cdot \mathrm{Fe}$ and $\mathrm{FeO}$. $\mathrm{CaO}$, $\mathrm{SiO}_{2}, \mathrm{MgO}, \mathrm{P}_{2} \mathrm{O}_{5}$, etc., contained in dust, are thought to be attributable to slag scattering although the quantities are very small.

Table 2 shows a typical example of slag composition at turn down. In this study, burst bubble particle and fumes generated from bulk metal are investigated. Although it is necessary to remove the effect of slag or additives scattering, for example, effect of $\mathrm{T} \cdot \mathrm{Mn}$ in slag on $\mathrm{T} \cdot \mathrm{Mn}$ in dust is little considering the composition of slag components shown in Table 2.

Table 3 shows a typical example of EPMA quantitative analysis of a dust particle $(<1 \mu \mathrm{m})$ in Fig. 8. Slag components are not contained in dust particles. In this study, dust particles composed of $\mathrm{Fe}$ as main component and no slag components are investigated.

\subsection{Change of Generation Rate of Dust in Blowing}

Fig. 1 shows a change of the generation rate of total dust and T.Fe, M.Fe, $\mathrm{FeO}$ and $\mathrm{Fe}_{2} \mathrm{O}_{3}$ all of which are the major components of dust in the blowing process. It is found therefrom that the general tendency is such that the generation rate of total dust increases sharply at the initial stage of blowing, is almost fixed in the middle stage, and decreases abruptly at the end of blowing. Though the generating behavior of $\mathrm{T} \cdot \mathrm{Fe}$ and $\mathrm{M} \cdot \mathrm{Fe}$ contained in dust is much the same as that of total dust, the generation rate of
$\mathrm{FeO}$ tends to increase relatively at the initial and the last stages of blowing. With respect to $\mathrm{Fe}_{2} \mathrm{O}_{3}$, such tendency is found that it comes out only at the beginning of blowing.

Fig. 2 shows a change of the generation rate of $\mathrm{T} \cdot \mathrm{Fe}$ in dust in the case of blowing with oxygen flow rate varicd. There is a tendency that the generation rate of $\mathrm{T} \cdot \mathrm{Fe}$ in dust incrcases in blowing with a high oxygen flow rate, and in any blowing operation the generating behavior of $\mathrm{T} \cdot \mathrm{Fe}$ in dust exhibits almost the same tendency as mentioned above. Moreover as stated above, the generation rate of total dust and that of $\mathrm{T} \cdot \mathrm{Fe}$ in dust show the same behavior and further, $\mathrm{T} \cdot \mathrm{Fe}$ is predominant in the total dust. Thus, the quantity of $\mathrm{T} \cdot \mathrm{Fe}$ generated in dust will be taken as an index of the quantity of dust generated later on.

In connection with the relation of dust generation rate $v s$, carbon concentration in molten stcel, E. T. Turkdogan et al., ${ }^{1,5,6)}$ and J. P. Morris et al., ${ }^{7)}$ have reported as follows based on test results from small furnaces.

That is, when $[\mathrm{C}]$ is about $2 \%$ or less (the former

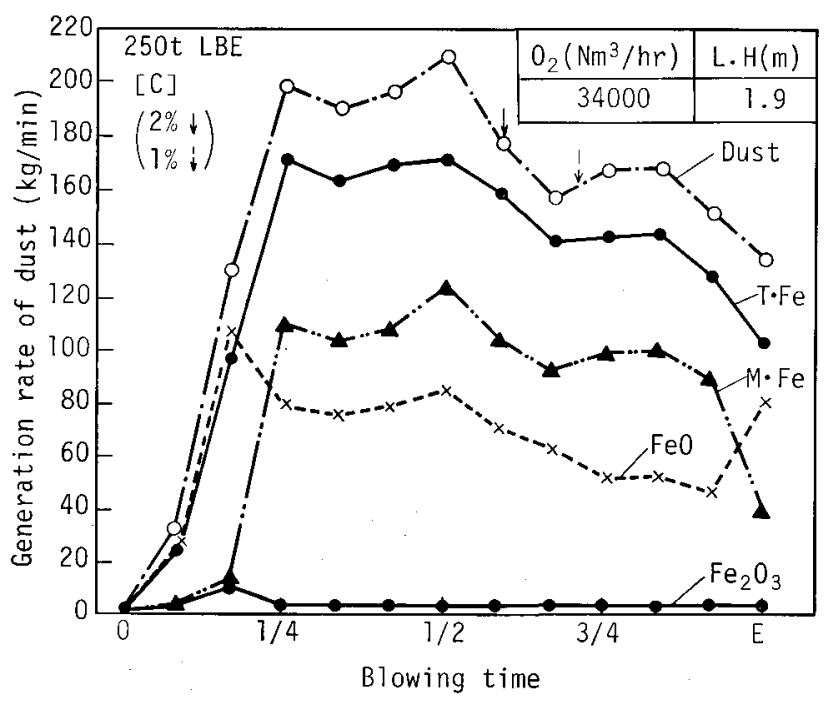

Fig. 1. Changes of generation rate of dust during blowing.

Table 2. Example of chemical composition of slag at turn down. (250 t LBE)

\begin{tabular}{llllllll}
\hline Component & $\mathrm{T} \cdot \mathrm{Fe}$ & $\mathrm{CaO}$ & $\mathrm{SiO}_{2}$ & $\mathrm{MnO}$ & $\mathrm{MgO}$ & $\mathrm{P}_{2} \mathrm{O}_{5}$ & $\mathrm{~S}$ \\
\hline $\begin{array}{l}\text { Chemical } \\
\text { comp. (\%) }\end{array}$ & 13.7 & 39.6 & 13.6 & 9.9 & 9.9 & 1.21 & 0.50 \\
\hline
\end{tabular}

Table 1. Example of chemical composition of dust. (250 $t$ LBE)

\begin{tabular}{cccccccccccc}
\hline Component & $\mathrm{T} \cdot \mathrm{Fe}$ & $\mathrm{M} \cdot \mathrm{Fe}$ & $\mathrm{FeO}$ & $\mathrm{Fe}_{2} \mathrm{O}_{3}$ & $\mathrm{~T} \cdot \mathrm{Mn}$ & $\mathrm{C}$ & $\mathrm{S}$ & $\mathrm{CaO}$ & $\mathrm{SiO}_{2}$ & $\mathrm{MgO}_{2}$ & $\mathrm{P}_{2} \mathrm{O}_{5}$ \\
\hline Chemical composition (\%) & $\mathbf{8 4 . 1 5}$ & 50.27 & 43.11 & 0.54 & 0.64 & 0.81 & 0.062 & 0.21 & 0.68 & 0.96 & 0.070 \\
\hline
\end{tabular}

Table 3. Example of EPMA quantitative analysis of a dust particle. $(1 \mu \mathrm{m})$

\begin{tabular}{ccccccccccc}
\hline Component & $\mathrm{C}$ & $\mathrm{Si}$ & $\mathrm{Mn}$ & $\mathrm{P}$ & $\mathrm{S}$ & $\mathrm{Ca}$ & $\mathrm{Mg}$ & $\mathrm{O}$ & $\mathrm{Fe}$ & $\mathrm{Total}$ \\
\hline Composition (\%) & 0.19 & $<0.02$ & 0.32 & $<0.02$ & $<0.02$ & $<0.02$ & $<0.02$ & 5.60 & 92.95 & 99.0 \\
\hline
\end{tabular}


report) and about $1.5 \%$ or less (the latter report), the dust generation rate decreases sharply, and when [C] exceeds the above percentages, the generation rate increases in proportion to the carbon concentration.

It has been clarified from the experimental results that although the generation rate of $\mathrm{T} \cdot \mathrm{Fe}$ in dust decreases somewhat from a condition where [C] is about 1 to $2 \%$ at the end of blowing, the dependency of the generation rate of $\mathrm{T} \cdot \mathrm{Fe}$ in dust on the carbon concentration in the blowing process is not so conspicuous as that seen in the aforesaid small furnace tests.

As a difference with the results obtained from the actual furnace test, no increase in fumes can be seen from the middle stage of blowing in the small furnace tests. It can be thought by the following consideration that the ratio of burst bubble particles in the quantity of dust generated in the small furnace test becomes higher than that of the actual furnace and the generation rate of $\mathrm{T} \cdot \mathrm{Fe}$ in dust depends greatly on the carbon concentration.

Namely in the small furnace, heat loss outside the furnace is generally serious and the atmospheric temperature in the furnace is low compared with the actual furnace. Further, in the small furnace tests, the hot spot temperature is about $2200^{\circ} \mathrm{C}^{19}$ which is quite low compared with the 2400 to $2500^{\circ} \mathrm{C}^{(22)}$ of

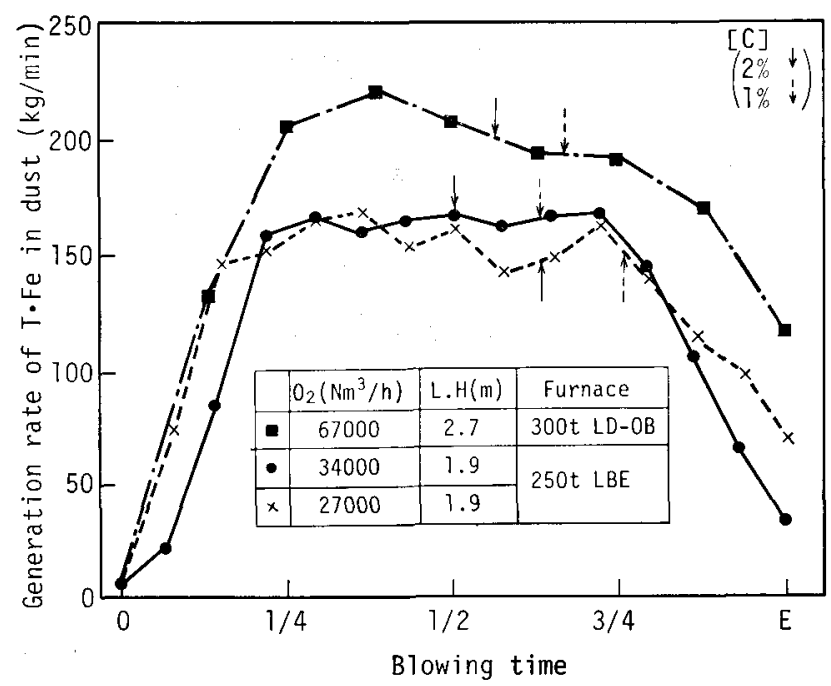

Fig. 2. Changes of generation rate of $\mathrm{T} \cdot \mathrm{Fe}$ in dust during blowing. the actual furnace. Therefore, the evaporation rate is supposed to lessen relatively. Incidentally, as will be described later, it is to be understood from the results of the actual furnace test that the phenomenon that the generation rate of $\mathrm{T} \cdot \mathrm{Fe}$ in dust attributable to burst bubble particles depends on the carbon concentration is similar to the phenomenon that the dust generation rate in the small furnace depends on the carbon concentration.

Moreover, the generation rate of $\mathrm{FeO}$ is relatively high at the initial and final stages of blowing and the rate of $\mathrm{Fe}_{2} \mathrm{O}_{3}$ is high at the initial stage of blowing. This can be judged to be traceable to the rate of $\mathrm{CO}_{2} /\left(\mathrm{CO}+\mathrm{CO}_{2}\right)$ in $\mathrm{BOF}$ exhaust gas being relatively high at the initial and final stages of blowing ${ }^{10)}$ and because of its oxygen potential being high, Fe contained in the fumes or burst bubble particles is oxidized.

\subsection{Effects of Blowing Conditions on Quantity of $\mathrm{T} \cdot \mathrm{Fe}$ in Dust}

3.3.1. Effect of Quantity of Additives for Slag Formation

As shown in Fig. 3, when the quantity of additives for slag formation is $20 \mathrm{~kg} / \mathrm{t}$ or more, no clear relation can be found between the quantity of dust generated and the quantity of additives for slag formation.

It can be supposed that if $20 \mathrm{~kg} / \mathrm{t}$ is added for slag formation, the generation of fumes or burst bubble particles is suppressed since the whole bath face is covered or a slag foaming level exists in the vicinity of $\mathrm{O}_{2}$ jet in excess of a certain value. There is also a report saying that when the quantity of additive for slag formation is small, the quantity of dust increases. ${ }^{11)}$ Consequently, there is a need to examine and pursue the effect of lower slag quantity level on dust generation.

\subsubsection{Effect by Top Blowing Oxygen Flow Condi- tion}

Fig. 4 shows a relation between an average dust generation rate at the middle of blowing (1/4 to $3 / 4$ of total blowing time) and a top blowing oxygen flow rates of 300-t and 250-t BOFs with combined blowing. Similarly, Fig. 5 shows a relation between an average dust generation rate at the middle of blowing and an apparent expansion area of top blowing $\mathrm{O}_{2}$ jet on the bath surface.
Fig. 3.

Effect of additive consumption on the total generation amount of $\mathrm{T} \cdot \mathrm{Fe}$ in dust.

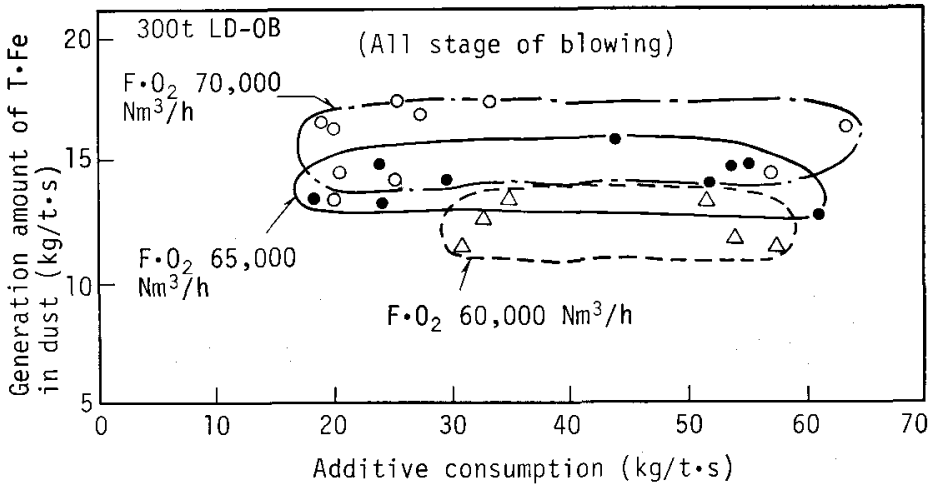


The apparent expansion area of the jet has been obtained from a free jet length obtained by Eqs. (1) to $(3)^{10)}$ and a jet angle of about $26^{\circ}$ obtained as $U / U_{m}=0.01$ by Eq. (4). ${ }^{12}$

$$
\begin{aligned}
h & =L_{G}-H_{c} \\
H_{c} / d_{o} & =4.12 P-1.86 \ldots \ldots \ldots \ldots \ldots \ldots \ldots \ldots \ldots \ldots \ldots \ldots \ldots \ldots \ldots \ldots \ldots \ldots \ldots \ldots \ldots \ldots \ldots \ldots \ldots \ldots \ldots \ldots \\
\mathrm{F} \cdot \mathrm{O}_{2} & =58.1 \times n A \times(P+1.033) \times 10^{4} \\
U / U_{m} & =\exp \left[-87(r / x)^{2}\right] \ldots \ldots \ldots \ldots \ldots \ldots \ldots
\end{aligned}
$$

where, $\quad A:$ Sectional area of lance nozzle $\left(\mathrm{m}^{2}\right)$

$d_{0}:$ Lance nozzle diameter $(\mathrm{cm})$

$\mathrm{F} \cdot \mathrm{O}_{2}$ : Oxygen flow rate $\left(\mathrm{Nm}^{3} / \mathrm{h}\right)$

$h$ : Free jet length $(\mathrm{cm})$

$H_{e}$ : Ultrasonic core length $(\mathrm{cm})$

$L_{G}:$ Distance between lance nozzle and molten metal surface $(\mathrm{cm})$

$n$ : Number of lance nozzles

$P$ : Pressure in front of lance nozzle $(\mathrm{kg} /$ $\mathrm{cm}^{3}$ )

$r$ : Radial distance in free jet $(\mathrm{cm})$

$U, U_{m}$ : Velocity of points $(x, r),(x, o)$, respectively, by cylindrical coordinates in free jet of $\mathrm{O}_{2}$ jet $(\mathrm{cm} / \mathrm{s})$

$x$ : Length of free jet from nozzle $(\mathrm{cm})$.

It can be learned from Figs. 4 and 5 that the higher the top blowing oxygen flow rate is, and, the larger the apparent expansion area of top blowing jet on the bath surface (that is, a soft blowing) at constant oxygen flow rate, the higher the generation rate of $\mathrm{T} \cdot \mathrm{Fe}$ in dust.

\subsection{Microscopic Observation of Dust}

\subsubsection{Appearance of Dust}

As the result of microscopic observation, it has been found that the bulk is fine particles of $1 \mu \mathrm{m}$ and less, though dust whose maximum particle size exceeds $100 \mu \mathrm{m}$ also exists.

When these are observed by an electron microscope, polygonal dust particles, ${ }^{13,14)}$ which have been said to be characteristic of fumes, can hardly be seen,

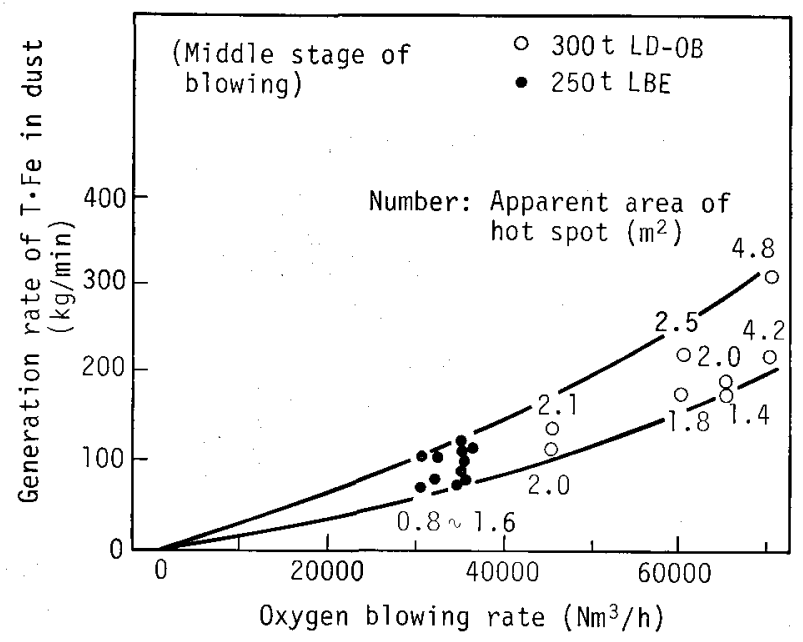

Fig. 4. Relation between generation rate of $\mathrm{T} \cdot \mathrm{Fe}$ in dust and oxygen blowing rate in the range of blowing time from $1 / 4$ to $3 / 4$. as shown in Fig. 6. This confirms that dust produced only by fumes is small as stated later.

\subsubsection{Particle Size Distribution of Dust}

Fig. 7 shows a typical example of measurement results of the particle size distribution of dust obtained by a centrifugal sedimentation measurement method. ${ }^{15)}$ The data acquired at the initial and middle stages of blowing and the results of this survey have revealed that at each stage of blowing, the ratio of coarse dust particles of $5 \mu \mathrm{m}$ and more is low and that of fine dust particles of $1 \mu \mathrm{m}$ and less is high.

\subsubsection{Relation between Composition of Components and Dust Particle Size}

It has been looked through a relation between the $[\mathrm{Mn}] /[\mathrm{Fe}]$ ratio in dust, partially the $[\mathrm{Mo}] /[\mathrm{Fe}]$ ratio of Mo-added blowing test heat and the dust particle size with a quantitative analysis made by EPMA about the concentrations of $[\mathrm{Fe}],[\mathrm{Mn}]$ and $[\mathrm{Mo}]$ every piece of dust particles. The relations are shown in Figs. 8 to 10. Moreover, for fine particles of

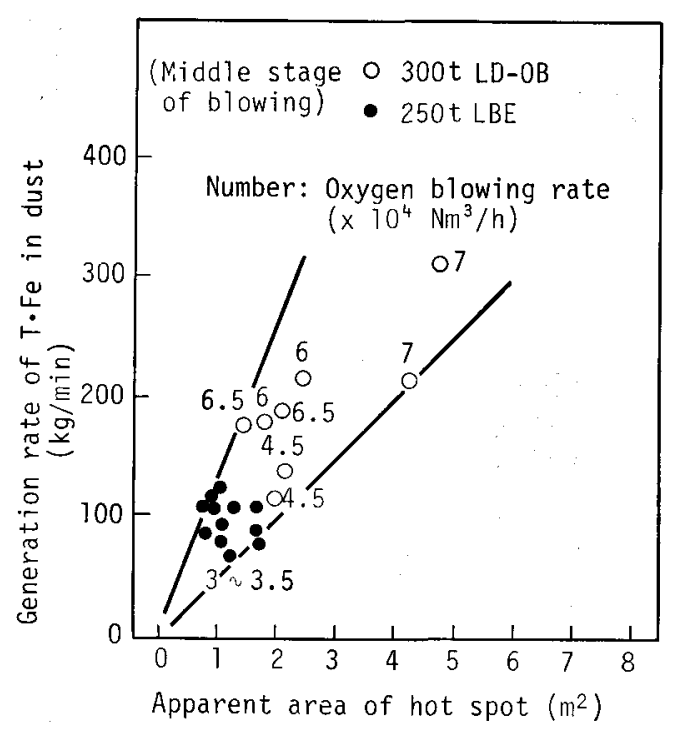

Fig. 5. Relation between generation rate of T.Fe in dust and apparent area of hot spot in the range of blowing time from $1 / 4$ to $3 / 4$.

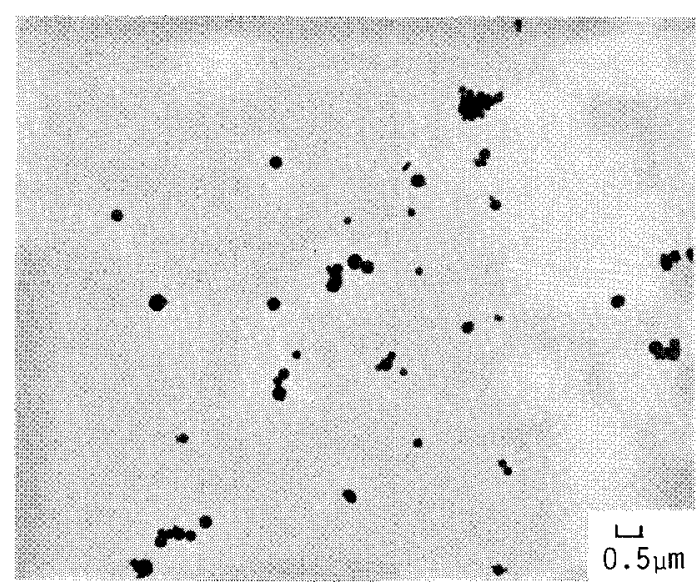

Fig. 6. Dust appearance by electron microscopy. $\quad(300 \mathrm{t}$ LD-OB) 


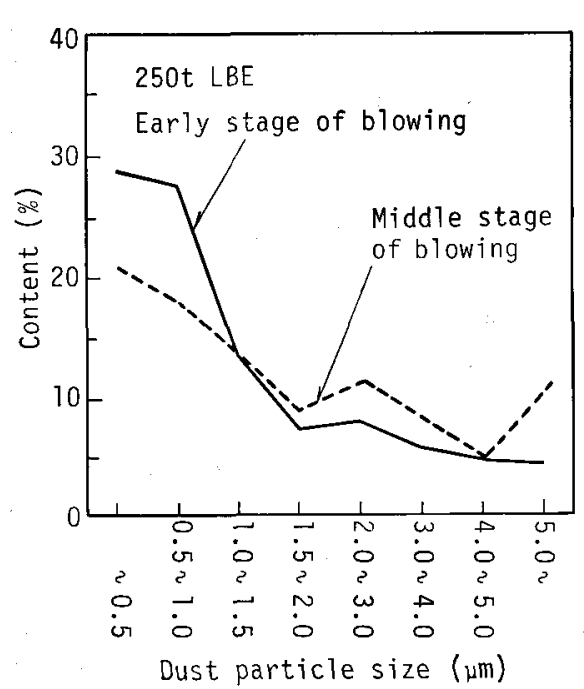

Fig. 7. Dust particle size distribution.

which size is under $0.5 \mu \mathrm{m}$, since a spot analysis by EPMA can not be done every piece as stated hereinabove, the $[\mathrm{Mn}] /[\mathrm{Fe}]$ ratio and the $[\mathrm{Mo}] /[\mathrm{Fe}]$ ratio in dust have been obtained by a line scan analysis of a coagulating part.

Figs. 8 and 9 show that when the dust particle size is as fine as $5 \mu \mathrm{m}$ or less, the smaller the dust particle size, the larger the $[\mathrm{Mn}] /[\mathrm{Fe}]$ ratio. The $[\mathrm{Mn}] /[\mathrm{Fe}]$ ratio in dust whose particle size is $1 \mu \mathrm{m}$ or less is about 5 to 20 times as much as that in the bath. Also, in respect of dust having particle size of 5 to 10 $\mu \mathrm{m}$, the $[\mathrm{Mn}] /[\mathrm{Fe}]$ ratio in dust is lower than that in the bath, which is minimum in all particle sizes. When the particle size becomes larger, the $[\mathrm{Mn}] /[\mathrm{Fe}]$ ratio in dust is approximately same to that in the bath.

The $[\mathrm{Mo}] /[\mathrm{Fe}]$ ratio shown in Fig. 10 indicates a tendency which is almost opposite to the $[\mathrm{Mn}] /[\mathrm{Fe}]$ ratio in Figs. 8 and 9, and when the dust particle size is as fine as $5 \mu \mathrm{m}$ or less, the smaller the dust particle size, the lower the $[\mathrm{Mo}] /[\mathrm{Fe}]$ ratio in dust.

The $[\mathrm{Mo}] /[\mathrm{Fe}]$ ratio of dust having particle size of $1 \mu \mathrm{m}$ or less is about 0.04 to 0.6 times as much as that in the bath. Also at a range of particle size from about 5 to $10 \mu \mathrm{m}$, the $[\mathrm{Mo}] /[\mathrm{Fe}]$ ratio in dust is greater than that in the bath, which is maximum in all particle sizes and when the particle size becomes larger, the $[\mathrm{Mo}] /[\mathrm{Fe}]$ ratio in dust is approximately same to that in the bath.

These reasons will be explained later. At any rate, the smaller the dust particle size, the higher the concentration of $\mathrm{Mn}$ in dust than the bath component concentration and the lower the concentration of Mo in dust than the bath component concentration. This indicates that not only the burst bubble particles but also the fumes are involved in the generation mechanism of dust. Namely, it can be surmised that most dust comprises the burst bubble particles and fumes but not only the burst bubble particles or fumes.

It can also be seen that the above fact indicates that the makeup ratio of fumes and burst bubble particles differs according to the dust particle sizes.

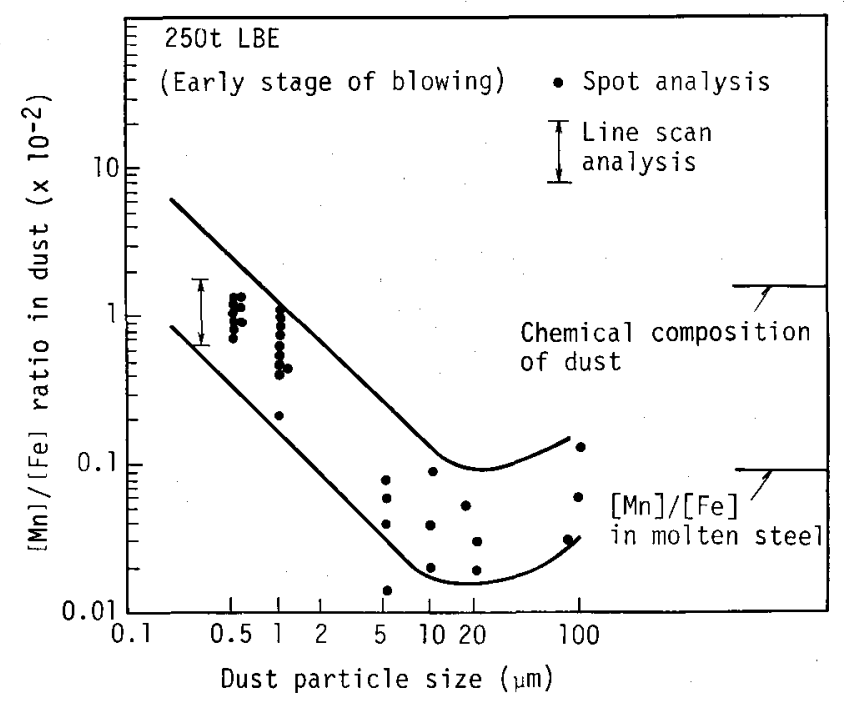

Fig. 8. Relation between dust particle size and $[\mathrm{Mn}] /[\mathrm{Fe}]$ ratio in dust by EPMA.

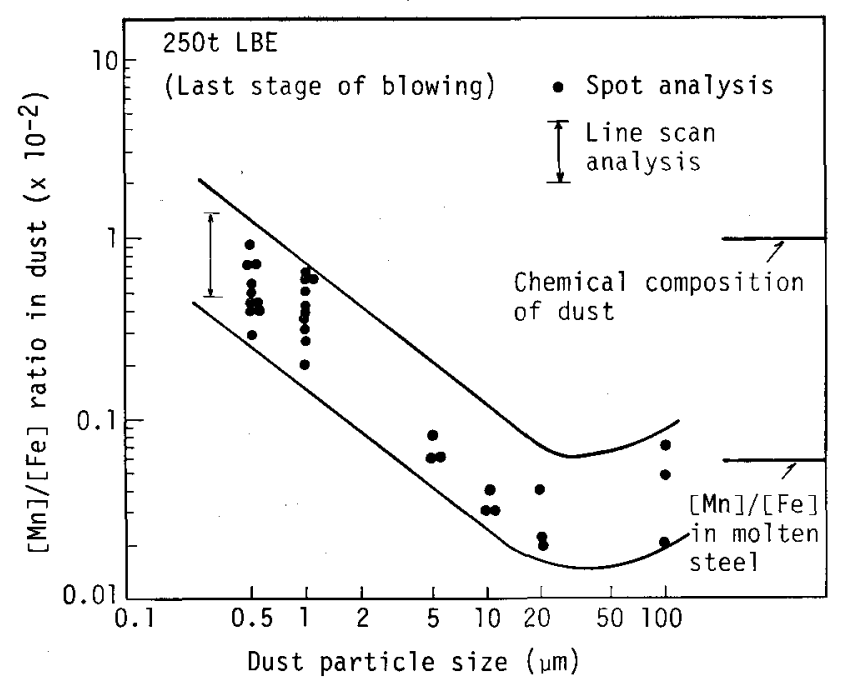

Fig. 9. Relation between dust particle size and $[\mathrm{Mn}] /[\mathrm{Fe}]$ ratio in dust by EPMA.

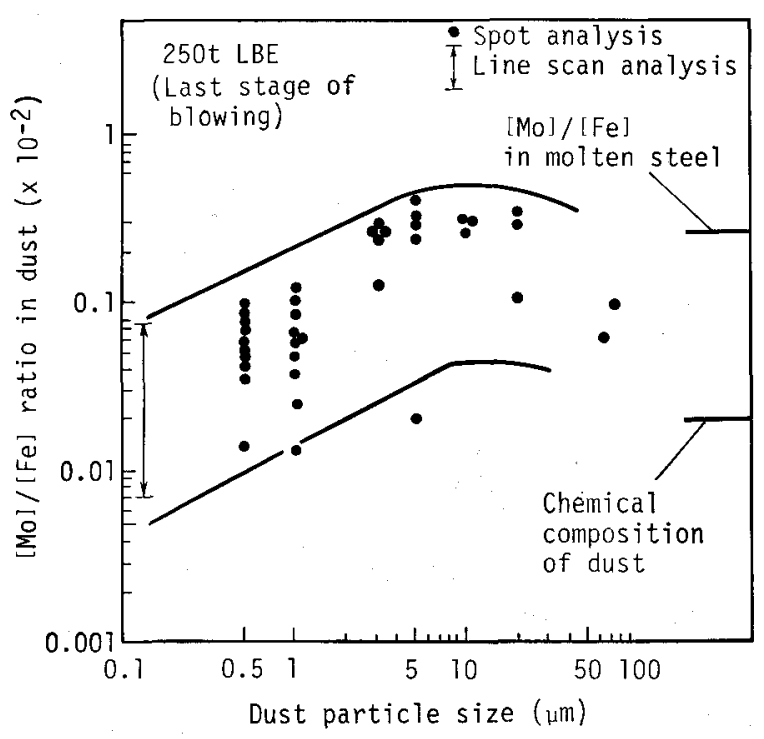

Fig. 10. Relation between dust particle size and $[\mathrm{Mo}] /[\mathrm{Fe}]$ ratio in dust by EPMA. 


\section{Discussion}

\subsection{Generalion Mechanism of Dust}

As shown in Figs. 8 and 9, from the fact that the $[\mathrm{Mn}] /[\mathrm{Fe}]$ ratio and the $[\mathrm{Mo}] /[\mathrm{Fe}]$ ratio in dust are changing continually with the dust particle sizes, the generation mechanism of dust can be supposed as follows. The fumes condense and mix with the burst bubble particles in a high-temperature exhaust gas, whereby dust is produced. In fact most dust particles are granular as shown in Fig. 6 and as the result of the state analysis by electron microscope, a dust particle having a form in which $\mathrm{MnO}$ is sticking to $\alpha$-Fe particle has been recognized as shown in Fig. 11 .

This indicates a condition where the fumes of $\mathrm{Mn}$ mix with the particles of $\mathrm{Fe}$ (burst bubble particles or Fe fumes) thereby to generate the dust particles.

The composition of components of dust produced as a result of the fumes having mixed with the burst bubble particles depends on a material balance between the composition of components of burst bubble particles which serve as nuclei when the fumes mix with the particles and the composition of components of fumes, and the composition of components evaporating from the burst bubble particles. It is possible that when the particle size of dust generated is small (in other words, when the burst bubble particles are small), the effect by the fumes is great. From a difference in vapor pressure, the $[\mathrm{Mn}] /[\mathrm{Fe}]$ ratio in dust increases, whereas the $[\mathrm{Mo}] /[\mathrm{Fe}]$ ratio decreases. Also, with the increase in the dust particle size (burst bubble particle size), the effect by the fumes decreases and at the same time, the particles are retained at a higher temperature. As a consequence, evaporation from the burst bubble nucleus proceeds and the [Mn]/ $[\mathrm{Fe}]$ ratio in dust becomes smaller than the concentration ratio in the bath while the $[\mathrm{Mo}] /[\mathrm{Fe}]$ ratio becomes larger. When the dust particle size (burst bubble particle size) becomes further large, the effect of the fumes condensing and mixing with the particles from the bath and the effect of evaporation from

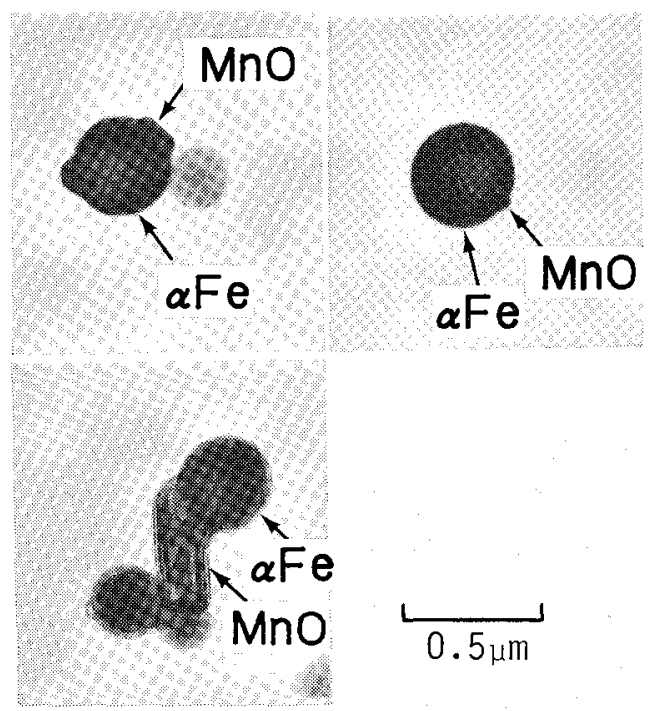

Fig. 11. Results of reaction between $\mathrm{Fe}$ and $\mathrm{Mn}$ particles by electron microscopy ( $300 \mathrm{t} \mathrm{LD}-\mathrm{OB}$ ). the burst bubble particles both become small. Also, the composition of dust components comes nearer the concentration ratio in the stccl and the $[\mathrm{Mn}] /[\mathrm{Fc}]$ ratio in dust increases again while the $[\mathrm{Mo}] /[\mathrm{Fe}]$ ratio decreases again.

Moreover, it is supposed that in the relation between dust particle size $v s$. the $[\mathrm{Mn}] /[\mathrm{Fe}]$ ratio and the $[\mathrm{Mo}] /[\mathrm{Fe}]$ ratio in dust, where the particle size is large, the $[\mathrm{Mn}] /[\mathrm{Fe}]$ ratio and the $[\mathrm{Mo}] /[\mathrm{Fe}]$ ratio in dust approximate the concentration ratio in the bath. However as shown in Figs. 8 to 10, there are particles with higher $[\mathrm{Mn}] /[\mathrm{Fe}]$ ratio in dust than the concentration ratio in the bath and also there are particles with lower $[\mathrm{Mo}] /[\mathrm{Fe}]$ ratio than the concentration ratio in the bath. These particles are deemed to be those affected greatly by the fumes condensing and coagulating. Further, from the fact that variation in the values of the $[\mathrm{Mn}] /[\mathrm{Fe}]$ ratio and the $[\mathrm{Mo} / /[\mathrm{Fe}]$ ratio in dust is great even if the particle size is the same, it can be guessed that the coagulation of the fumes and the burst bubble particles is occurring in a nonuniform condition in the atmosphere.

\subsection{Contribution Ratio of Fumes and Burst Bubble Parti- cles to the Generation of Dust}

It might be possible to obtain the ratio of burst bubble particles in the generation of dust from the consideration on the thickening of $\mathrm{Mn}$ in the dust by Eqs. (5) and (7). However, in fact it is difficult for the following reasons:

(1) Since the fume generating site and the detail of its temperature distribution are not clear, it is impossible to obtain what extent $\mathrm{Mn}$ thickens into dust.

(2) As for $\mathrm{Mn}$, the evaporation rate is controlled by an evaporation reaction rate on the surface at relatively low temperature of $1450^{\circ} \mathrm{C}$ as a border, and also by diffusion in the molten metal at high temperature. ${ }^{17)}$ As the evaporation behavior differs according to the temperatures at the fume generating site, it is hard to analyze. Then, as stated in the previous experimental method, the ratio of burst bubble particles in generation of dust has been obtained from Eqs. (5) to (7) based on the concentration of Mo contained in dust with Mo having a quite lower vapor pressure than Fe as a tracer.

$$
\begin{aligned}
& R_{f}\left(C_{i} / \mathrm{Fe}\right)_{f}+R_{b}\left(C_{i} / \mathrm{Fe}\right)_{b}=\left(C_{i} / \mathrm{Fe}\right)_{D} \\
& R_{f}+R_{b}=1 \quad \ldots \ldots \ldots \ldots \ldots \ldots \ldots \ldots \ldots \ldots \ldots \ldots \ldots \ldots \ldots \ldots \ldots \ldots \ldots \ldots \ldots \ldots \ldots \ldots \ldots \ldots \ldots \ldots \\
& \left(C_{i} / \mathrm{Fe}\right)_{b} \fallingdotseq\left(C_{i} / \mathrm{Fe}\right)_{m}
\end{aligned}
$$

where, $\quad C_{i}$ : Concentration of component of $i$

$$
\left(C_{i} / \mathrm{Fe}\right)_{f},\left(C_{i} / \mathrm{Fe}\right)_{b},\left(C_{i} / \mathrm{Fe}\right)_{D},\left(C_{i} / \mathrm{Fe}\right)_{m}: \text { Ratio of }
$$
concentration of component of $i$ to concentration of $\mathrm{Fe}$ in fumes, burst bubble particles, dust and bath, respectively

(For Mo and $\mathrm{Pt},(\mathrm{Mo} / \mathrm{Fe})_{f} \fallingdotseq 0$ and $\left.(\mathrm{Pt} / \mathrm{Fe})_{f} \fallingdotseq 0\right)$

$R_{f}, R_{b}$ : Ratio of contribution to generation of fumes and burst bubble particles, respectively.

Although the vapor pressure of Mo is very low and 
its evaporation is negligible, when the ratio of burst bubble particles in dust is obtained with Mo as a tracer, $\mathrm{MoO}_{3}$ having high vapor pressure ${ }^{15}$ ) would be generated at the hot spot during blowing. This provides a possibility of the value of ratio of burst bubble particles being evaluated higher than the actual value from examination with the expressions (8) to (12).

$$
\begin{aligned}
& {[\mathrm{Mo}]+3 / 2 \mathrm{O}_{2}=\mathrm{MoO}_{3}(\mathrm{~g})} \\
& \Delta G^{\circ}=-119600+26.22 T^{18)}(\mathrm{cal} / \mathrm{mol})
\end{aligned}
$$

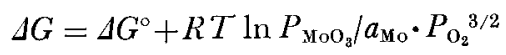

$$
\begin{aligned}
& a_{\mathrm{Mo}}=\gamma_{\mathrm{Mo}}[\% \mathrm{Mo}] \\
& \ln \gamma_{M_{0}} \doteqdot-0.102[\% \mathrm{G}]
\end{aligned}
$$

Then, assuming that $P_{\mathrm{MoO}_{3}}$ is $10^{-2} \sim 1$ and $P_{\mathrm{O}_{2}}$ is $0.1 \sim$ 1 , when $\Delta G$ is obtained by substituting the conditions; $[\mathrm{C}]=4 \%,[\mathrm{Mo}]=0.30 \%, 1300 \sim 2450^{\circ} \mathrm{C}$ and $[\mathrm{C}]=$ $1 \%,[\mathrm{Mo}]=0.30 \%, 1600 \sim 2450^{\circ} \mathrm{C}$ for the Eqs. (9) to (12), $\Delta G$ becomes smaller than $0, \Delta G<0$ in any case.

However, the effect by the evaporation of $\mathrm{MoO}_{3}$ during blowing is assumed to be negligible since it is very slight for the following reason.

As shown in Fig. 10, the relation between the [Mo]/ [Fe] ratio in dust and the dust particle size is almost opposite to the relation between the $[\mathrm{Mn}] /[\mathrm{Fe}]$ ratio in dust and the dust particle size. Further, in the decarburization test using a $20 \mathrm{~kg}$ smelting furnace, the behavior of dust has been checked at a time when $\mathrm{Pt}$, which has lower vapor pressure than $\mathrm{Fe}$ and makes it hard to generate such oxide having high vapor pressure as Mo oxide, was added together with Mo. Fig. 12 shows the relation between the $[\mathrm{Pt}] /[\mathrm{Fe}]$ ratio in dust and the dust particle size. The relation between the $[\mathrm{Pt}] /[\mathrm{Fe}]$ ratio in dust and the dust particle size in the test with the $20 \mathrm{~kg}$ smelting furnace exhibits the same tendency as with the relation between the $[\mathrm{Mo}] /[\mathrm{Fe}]$ ratio in dust and the dust particle size in Fig. 10 showing the results obtained from the actual furnace. It can be judged from the above facts that the effect by the generation and evaporation of $\mathrm{MoO}_{3}$ is relatively small. This is because, although the detail of the behavior of generation and evaporation of $\mathrm{MoO}_{3}$ at the hot spot is not clear, that $\mathrm{MoO}_{3}$, even

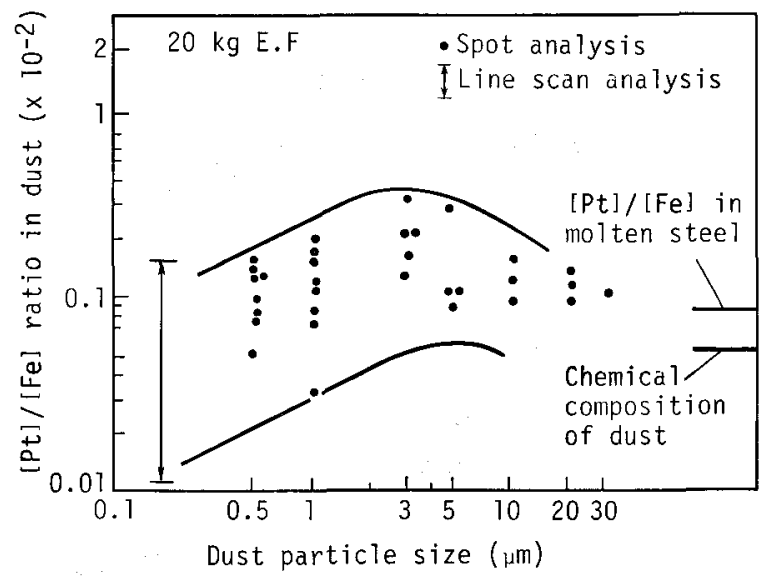

Fig. 12. Relation between dust particle size and $[\mathrm{Pt}] /[\mathrm{Fe}]$ ratio in dust by EPMA. if having been produced, goes into the bath or the bath gas emulsion layer and probably, it is discharged into the atmosphere in the furnace together with $\mathrm{CO}$ gas current produced by a decarburizing reaction.

It is considered from Eqs. (13) to (19) that quite a large quantity of $\mathrm{MoO}_{3}$ produced once at the hot spot is reduced before being discharged into the furnace internal atmosphere by reaction with $\mathrm{CO}$ or [C] and returns into the bath as [Mo].

$$
\begin{aligned}
& \mathrm{MoO}_{3}(g)+3 \mathrm{CO}=[\mathrm{Mo}]+3 \mathrm{CO}_{2} \\
& \Delta G^{\circ}=80500-34.41 T(\mathrm{cal} / \mathrm{mol}) \\
& \Delta G=\Delta G^{\circ}+R T \ln a_{\mathrm{Mo}} \cdot P_{\mathrm{Co}_{2}}{ }^{3} / a_{\mathrm{MoO}_{3}} \cdot P_{\mathrm{Co}^{3}} \\
& \mathrm{MoO}_{3}(g)+[\mathrm{C}]=[\mathrm{Mo}]+3 \mathrm{CO} \quad \ldots \ldots \ldots \ldots \\
& \Delta G^{\circ}=19700-55.8 T(\mathrm{cal} / \mathrm{mol}) \\
& \Delta G=\Delta G^{\circ}+R T \ln a_{\mathrm{Mo}} \cdot P_{\mathrm{co}^{3}} / P_{\mathrm{MoO}_{3}} \cdot a_{c}{ }^{3} \ldots \\
& \ln \gamma_{c} \fallingdotseq 0.19[\% \mathrm{C}] \ldots \ldots \ldots \ldots \ldots \ldots \ldots \ldots \ldots \ldots
\end{aligned}
$$

Then, since it is surmised from Eqs. (13) to (15) that $P_{\mathrm{CO}_{2}}=0$ and $P_{\mathrm{CO}}=1$ and further from Eqs. (16) to (19) that $P_{\mathrm{OO}}=1$, assuming that $P_{\mathrm{MOO}_{3}}$ is $10^{-2} \sim 1$ in both cases, when $G$ is obtained in the same conditions of [C], [Mo] and temperature as in the examination with Eqs. (8) to (12), $\Delta G$ becomes smaller than 0, $\Delta G<0$. Table 4 shows the ratio of burst bubble particles in generation of dust at the last stage of blowing in the test performed with molybdic ore added.

In the test, the blowing was made twice and the ratio of burst bubble particles at the last stage of blowing can be evaluated maximum 10.5 and $21.1 \%$, respectively. In other words, it indicates that the ratio of fumes in the generation of dust is very high at the last stage of blowing.

Further, the ratio of burst bubble particles during the period of blowing was obtained in a test performed with Fe-Mo alloy added before blowing. The results are shown in Fig. 13. It can be learned from Fig. 13 that the ratio of burst bubble particles is high at the initial stage of blowing and decreases with the lapse of blowing time. The ratio of burst bubble particles at the last stage of blowing is about $1 / 3$ of that at the initial stage of blowing, and this is in accord with a tendency that the ratio of burst bubble particles is low at the end of blowing in the case of the test made with molybdic ore added. Also, from the generation rate of $\mathrm{T} \cdot \mathrm{Fe}$ in dust and the ratio of burst bubble particles obtained by the above method, a change of the generation rate of $\mathrm{T} \cdot \mathrm{Fe}$ in dust during blowing attributable to the fumes or burst bubble particles was obtained. The results are shown in Fig. 14. As will be apparent from Fig. 14, the generation rate of $\mathrm{T} \cdot \mathrm{Fe}$ in dust attributable to the fumes is low

Table 4. Burst bubble dust ratio at end point. (Mo added heat)

\begin{tabular}{ccccc}
\hline & \multicolumn{2}{c}{ Mo, Fe in dust $(\%)$} & $\begin{array}{c}\text { Mo in } \\
\text { molten } \\
\text { steel }(\%)\end{array}$ & $\begin{array}{c}\text { Burst } \\
\text { bubble dust } \\
\text { ratio }(\%)\end{array}$ \\
\hline 1 & 0.02 & 72.32 & 0.27 & 10.5 \\
2 & 0.05 & 78.66 & 0.30 & 21.1 \\
\hline
\end{tabular}


at the initial stage of blowing, increases progressively with the lapse of blowing time and decreases again at the end of blowing.

On the other hand, the generation rate of $\mathrm{T} \cdot \mathrm{Fe}$ in dust attributable to the burst bubble particles increases little by little from the initial stage but decreases from the middle stage of blowing. The reason why the quantity of T.Fe in dust attributable to the fumes is small at the initial stage and increases with the lapse of blowing time would be that the evaporation of $\mathrm{T} \cdot \mathrm{Fe}$ in dust from the bath or spitting particles or burst bubble particles increases according to the rise of the bath temperature and atmospheric temperature and further, that the bath temperature at the hot spot and its vicinity rises with the lapse of blowing time..$^{23)}$ For this, it is necessary to check the change in the hot spot temperature during blowing.

Moreover, the reason why the quantity of T.Fe in dust attributable to the fumes decreases at the end of blowing would be that $\mathrm{FeO}$ is produced on the bath surface whereby the evaporation of $\mathrm{Fe}$ is obstructed. ${ }^{1,5,6)}$

Furthermore, the reason why the generation rate of $\mathrm{T} \cdot \mathrm{Fe}$ in dust attributable to the burst bubble particles increases progressively from the initial stage of blowing might be that the rate corresponds to the decarburizing rate and the reason why the generation rate of $\mathrm{T} \cdot \mathrm{Fe}$ in dust attributable to the burst bubble particles decreases slowly in the time of maximum decarburization rate at the middle stage of blowing can be thought that slag foaming proceeds ${ }^{20)}$ and the

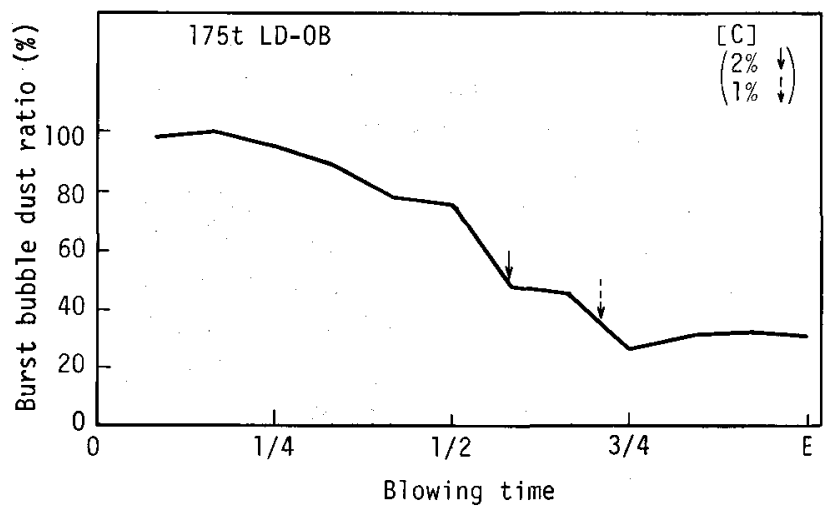

Fig. 13. Changes of burst bubble dust ratio during blowing. scattering into the atmospheric gas of burst bubble particles is prevented. At the last stage of blowing, though the slag foaming decreases in general, the generation rate of burst bubble particles may lower since the decarburizing rate decreases.

When the ratio of the quantity of $\mathrm{T} \cdot \mathrm{Fe}$ generated in dust attributable to the burst bubble particles to the total quantity of $\mathrm{T} \cdot \mathrm{Fe}$ generated in this test blowing is obtained, it becomes $52 \%$ approximately.

Details of a relation between the ratio of burst bubble particles taking in the quantity of dust generated and blowing conditions, the quantity of slag and slag foaming condition have to be examined further hereafter. However, as a basic idea of the step which reduces the quantity of dust generated, it will be important to produce a slag at an early time at the initial stage of blowing for decreasing dust attributable to the burst bubble particles and cool down the hot spot from the middle stage to the last stage of blowing to prevent dust attributable to the fumes from being generated.

\section{Conclusion}

By investigation of the generating behavior of dust in BOF with combined blowing, the dust generating mechanism was looked into. As a result, the following have been made clear:

(1) BOF dust is generated because of fumes condensing and mixing with burst bubble particles.

(2) The ratio of burst bubble particles in the dust is high at the initial stage of blowing and lowers with the lapse of blowing time and at the last stage of blowing, the ratio of fumes increases. Thus, for reducing the quantity of dust generated, it will be effective to produce a slag as early as possible at the initial stage and to cool down a hot spot from the middle stage of blowing.

\section{REFERENCES}

1) E. T. Turkdogan and L. E. Leake: J. Iron Steel Inst., 192 (1959), 162.

2) H. Kosmider, H. Ne u ha us and P. E. Hardt: J. Iron Steel Inst., 193 (1959), 6.

3) C. Holden: J. Iron Steel Inst., 193 (1959), 93.

4) K. Knaggs and J. M. Slater: J. Iron Steel Inst., 193 (1959), 211.

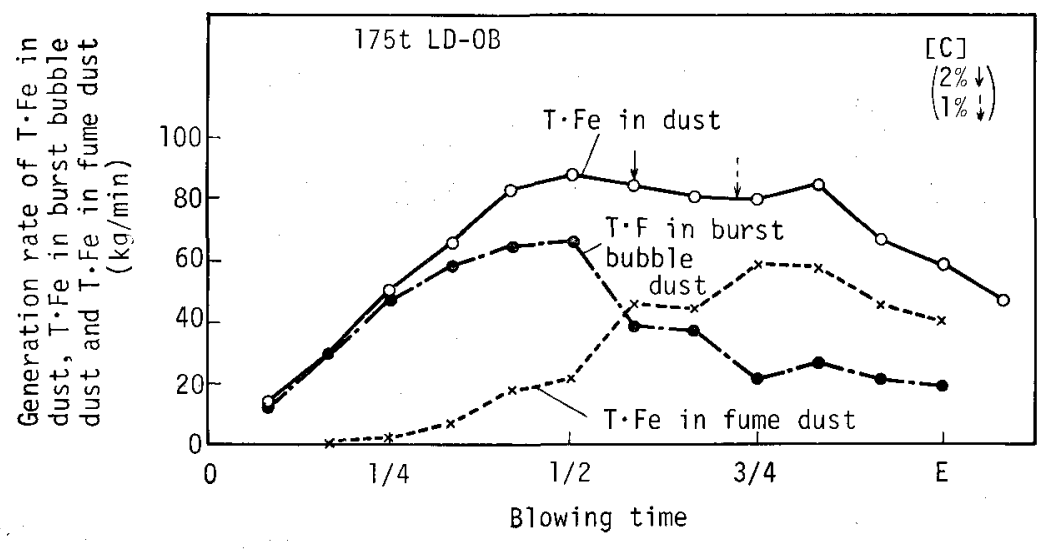

Fig. 14.

Changes of generation rate of $T \cdot F e$ in fume dust and T.Fe in burst bubble dust during blowing. 
5) E. T. Turkdogan, P. Grieveson and L. S. Darket: J. Met., 14 (1962), 521.

6) R. E. Bathes: J. Iron Steel Inst., 201 (1963), 747.

7) J. P. Morris, J. P. Riott and E. G. Illig: J. Met., 18 (1966), 303.

8) A. F. Ellis and J. Glover: J. Iron Steel Inst., 209 (1971), 598.

9) H. Trenkler and H. F. Hauttmann: Met. Prog., 69 (1956), 49.

10) M. Hirai, R. Tsujino, T. Mukai, T. Harada and M. Omori: Tetsu-to-Hagané, 73 (1987), 41.

11) S. Kohrogi, T. Matsuo and S. Masuda: Tetsu-to-Hagané, 71 (1985), S986.

12) J. M. Beér and N. A. Chigier: Combustion Airdynamics, Nippon Netsuenergy Kyokai, Tokyo, (1974).

13) R. Meldau: Arch. Eisenhüttenw., 27 (1956), 673.

14) T. Yoshida and K. Akashi: Tetsu-to-Hagané, 68 (1982), 1502.

15) Zouryu-binran, ed. by Japan Powder Ind. Soc., Ohmu-sha, Tokyo, (1975).
16) Metal Data Book, ed. by Japan Inst. Metals, Maruzen, Tokyo, (1974).

17) R. G. Ward and T. D. Aurini: J. Iron Steel Inst., (1966), 920.

18) J. F. Elliot, M. Gleiser and V. Ramakrishna: Thermochemistry for Steelmaking, Pergamon Press, New York, (1963).

19) T. Ohno, H. Ono and M. Okamura: Tetsu-to-Hagané, 72 (1986), S239; Trans. Iron Steel Inst. Jpn., 26 (1986), B312.

20) M. Tachikawa, M. Shimada, M. Ishibashi and T. Shiraishi: Tetsu-to-Hagané, (1974), A19.

21) T. Fukushima: Electron Beam Micro Analysis, Nikkan Kogyo Shinbunsha, Tokyo, (1987).

22) H. Krainer: Tetsu-to-Hagané, 51 (1965), 1194.

23) V. I. Yavoiskii: Sleel in USSR, (1971), October, 779.

(Originally published in Tetsu-to-Hagané, 74 (1988), 1954, in Japanese) 